\title{
Membrane cholesterol modulates cochlear electromechanics
}

\author{
William E. Brownell • Stefan Jacob • \\ Pierre Hakizimana • Mats Ulfendahl • \\ Anders Fridberger
}

Received: 3 December 2010 /Revised: 10 February 2011 / Accepted: 15 February 2011 /Published online: 4 March 2011

(C) The Author(s) 2011. This article is published with open access at Springerlink.com

\begin{abstract}
Changing the concentration of cholesterol in the plasma membrane of isolated outer hair cells modulates electromotility and prestin-associated charge movement, suggesting that a similar manipulation would alter cochlear mechanics. We examined cochlear function before and after depletion of membrane cholesterol with methyl- $\beta$ cyclodextrin $(\mathrm{M} \beta \mathrm{CD})$ in an excised guinea pig temporal bone preparation. The mechanical response of the cochlear partition to acoustic and/or electrical stimulation was monitored using laser interferometry and time-resolved confocal microscopy. The electromechanical response in untreated preparations was asymmetric with greater displacements in response to positive currents. Exposure to $\mathrm{M} \beta \mathrm{CD}$ increased the magnitude and asymmetry of the response, without changing the frequency tuning of sound-evoked mechanical responses or cochlear microphonic potentials. Sodium salicylate reversibly blocked the enhanced electromechanical response in cholesterol depleted preparations. The increase of sound-evoked vibrations during positive current injection was enhanced following $\mathrm{M} \beta \mathrm{CD}$ in some preparations. Imaging was used to assess cellular integrity which remained unchanged after several hours of exposure to $\mathrm{M} \beta \mathrm{CD}$ in several
\end{abstract}

\section{W. E. Brownell $(\square)$}

Bobby R. Alford Department of Otolaryngology—Head and Neck

Surgery, Baylor College of Medicine,

One Baylor Plaza,

Houston, TX 77030, USA

e-mail: brownell@bcm.tmc.edu

S. Jacob $\cdot$ P. Hakizimana $\cdot$ M. Ulfendahl $\cdot$ A. Fridberger

Department of Clinical Science, Intervention and Technology,

Center for Hearing and Communication Research,

Karolinska Institutet,

M1 Karolinska University Hospital,

17176 Stockholm, Sweden preparations. The enhanced electromechanical response reflects an increase in outer hair cell electromotility and may reveal features of cholesterol distribution and trafficking in outer hair cells.

Keywords Methyl- $\beta$-cyclodextrin $(\mathrm{M} \beta \mathrm{CD})$ - Salicylate . Interferometry - Time-resolved confocal microscopy Prestin-associated charge movement · Filipin · Hair cell . Membrane - Electrical stimulation - Intramembranous charge movement $\cdot$ Guinea pig $\cdot$ Cochlea $\cdot$ Hearing $\cdot$ Aging
Abbreviations
OHC Outer hair cell
MEM Minimum essential medium
M $\beta C D$ Methyl- $\beta$-cyclodextrin
NaSal Sodium salicylate

\section{Introduction}

Outer hair cell $(\mathrm{OHC})$ electromotility contributes to the movements of the cochlear partition $[20,36]$ consistent with a presumed role of OHCs in counteracting the effects of viscous damping $[4,6]$. A membrane-based motor in the $\mathrm{OHC}$ lateral wall is responsible for electromotility $[6,8,9$, $13,25,29]$. This motor converts the energy in the transmembrane electric field directly into mechanical energy and can generate forces at frequencies approaching $80 \mathrm{kHz}$ [19]. Prestin (SLC26A5) is an integral membrane protein found in OHC membranes [2, 5, 33, 56, 57] and is an important component of the membrane motor [31]. Prestin introduces a reactive component to the total membrane charge movement that is phase-shifted relative to the ohmic charge through ion channels [50]. This reactive or 
displacement current is often used as an experimental measure of prestin function.

We have previously shown that membrane cholesterol content affects prestin-associated charge movement in both OHCs [42] and human embryonic kidney (HEK) 293 cells expressing prestin [42, 46, 49]. A hyperpolarizing shift and decrease in the total amount of the prestin-associated charge moved is linearly related to increases in membrane cholesterol [46].Cholesterol comprises a substantial portion of eukaryotic cell membranes, accounting for $35 \%$ to $45 \%$ of membrane lipids $[3,12]$. Cholesterol distribution in the plasma membrane varies and in many cells its concentration is elevated in membrane rafts. The $\mathrm{OHC}$ is unusual in that its lateral wall plasma membrane contains less cholesterol than its basal or apical membranes and conventional rafts are not observed [7, 18, 37, 38, 42, 44].

Cholesterol dependent changes in OHC function would be expected to modulate cochlear function, specifically cochlear electromechanics. Increases and decreases of membrane cholesterol affect the production of distortion product otoacoustic emissions [42] consistent with membrane cholesterol playing a role in cochlear mechanics. Further support for a role in cochlear function comes from the fact that $\mathrm{OHC}$ membrane cholesterol concentration decreases during $\mathrm{OHC}$ development [42] over the same time frame as the onset and maturation of $\mathrm{OHC}$ electromotility $[5,23]$. In this study, we examine the effect of depleting membrane cholesterol on electrically and/or acoustically evoked movements of the cochlear partition in a well-characterized excised temporal bone preparation.

\section{Materials and methods}

\section{Animal preparation}

All animal procedures used in this study were approved by the local ethics committee (permit N460/09). Albino guinea pigs of both sexes, weighing 250-400 g, were anesthetized, decapitated, and the temporal bone quickly removed and fixed in a custom-made holder. The bulla was gently opened, followed by submersion of the preparation in oxygenated tissue culture medium (Minimum Essential Medium (MEM) with Earle's balance salts-Sigma; supplemented with $25 \mathrm{mM}$ HEPES, $5 \mathrm{mM} \mathrm{NaHCO} 3,25 \mathrm{mM}$ $\mathrm{NaCl} ; \mathrm{pH}=7.3 ; 0.33$ osM $/ \mathrm{kg}$ ). The holder prevented leakage of MEM into the external ear canal when the preparation was submerged and allowed the acoustic stimulation of the preparation with sound. The fluid-filled middle ear attenuates the effective sound pressure by approximately $30 \mathrm{~dB}$ [10]. Polyethylene tubing inserted into an opening in the basal turn of the cochlea (Fig. 1a) connected scala tympani with an elevated reservoir of oxygenated MEM. The perfusion system kept the preparation vital for up to $4 \mathrm{~h}$ and was also used to deliver pharmaceuticals. Measurements of vibrations and electrical potentials were made through a second opening in the otic capsule over scala vestibuli in turn 4 near the cochlear apex (Fig. 1b). The apical opening served as an exit for the perfusate and was also used to advance microelectrodes into scala media (Fig. 1b). All experiments were carried out at room temperature $\left(\sim 21^{\circ} \mathrm{C}\right)$.

Recordings typically began approximately $25 \mathrm{~min}$ after decapitation when the preparation still had a positive endocochlear potential (EP) of $10-30 \mathrm{mV}$. The EP decreased with time and was approximately $0 \mathrm{mV} 1 \mathrm{~h}$ after decapitation. In order to monitor the condition of the preparations, we repeatedly measured the amplitude of the cochlear microphonic potential at different frequencies.

\section{Interferometry}

A custom-made interferometer [27] equipped with a $25 \times$ water immersion lens [35] was used to measure the acoustically and electrically evoked movements of the organ of Corti. Application of artificial reflectors was not required and the noise floor of the system was well below the measured vibration amplitudes. For acoustic stimulation, we used a windowed $200 \mathrm{~ms}$ five tone complex, avoiding the frequencies of potential distortion products. A stepping protocol was used for the electrical stimulation. Each recording began with a $50-\mathrm{ms}$ interval at $0 \mu \mathrm{A}$; the current was then stepped to the desired value $(1-30 \mu \mathrm{A})$ and held constant for $100 \mathrm{~ms}$, followed by a step back to the $0 \mu \mathrm{A}$ level (Fig. 1c). Charge buildup in scala media was avoided by placing a second 100 -ms-long current pulse of opposite polarity outside of the measurement window.

Time-resolved confocal microscopy

Hair cells were stained with RH795 (Invitrogen, The Netherlands; [17] delivered through the perfusion system at the beginning of the experiment. An upright laser scanning microscope (LSM 510, Zeiss, Germany), equipped with a $40 \times$ water immersion lens ( $0.8 \mathrm{NA}$, Zeiss, Germany), was used to acquire a continuous series of 37 images. Each series required approximately $40 \mathrm{~s}$ at the frame size and scanning speed used. A pure tone was used for acoustic stimulation and a square wave of approximately $5 \mathrm{~Hz}$ and $50 \%$ duty cycle was used for electrical stimulation. Hence, the electrical stimulus alternated between positive and negative current during the image acquisition, which was locked to the acoustic and electric stimuli, as described previously [26]. For every pixel in the image series the phase of the acoustic stimulus and of the electrical stimulus were known. Using Fourier rows, images 


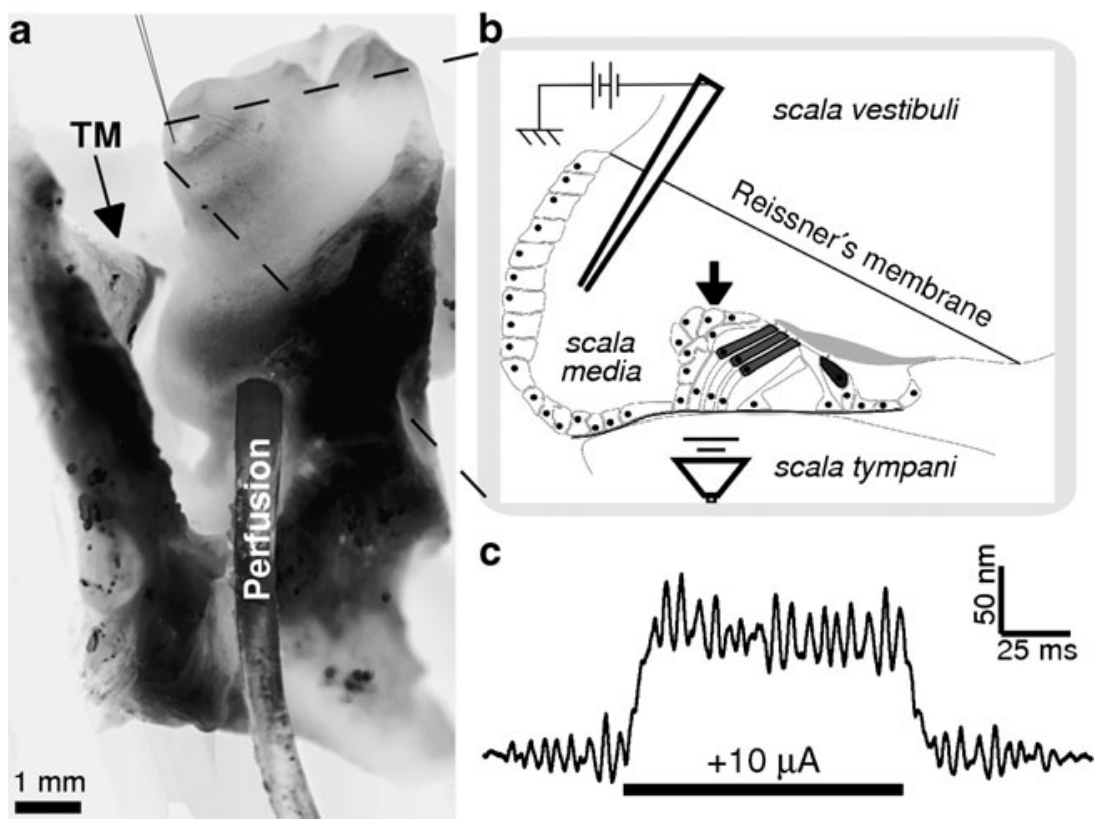

Fig. 1 Experimental methods. a Photomicrograph of excised temporal bone preparation. Tympanic membrane $(T M)$ and malleus are visible on the left. A perfusion tube is inserted through an opening into the scala tympani in the basal turn of the cochlea and oxygenated artificial perilymph is introduced under $\sim 10-\mathrm{cm}$ pressure. The endpiece of the tubing has a smaller diameter and the hole in the cochlea is smaller than the visible tubing. Perfusion solutions exit through an opening in the apical turn of the cochlea (visible near the cochlear apex). Optical recordings of cochlear movements are made and a current stimulus/CM recording micropipette is inserted into the scala

for positive and negative current stimulation were reconstructed at 12 equally spaced acoustic phases between 0 and $2 \pi$. Motion was estimated based on the computation of the optical flow between images of consecutive phases [21].

\section{Electrodes}

Borosilicate electrodes were freshly pulled, filled with an endolymph-like solution $\left(1.3 \mathrm{mM} \mathrm{NaCl}, 31 \mathrm{mM} \mathrm{KHCO}_{3}\right.$, $23 \mu \mathrm{M} \mathrm{CaCl}_{2}, 128.3 \mathrm{mM} \mathrm{KCl} ; \mathrm{pH}=7.4 ; 0.30 \mathrm{osM} / \mathrm{kg}$ ) and beveled to an impedance of approximately $2 \mathrm{M} \Omega$. Microphonic potentials were measured with an IX1 amplifier (Cornerstone, Dagan Corp., USA, equipped with $10 \times$ head stage) and digitized with a 16-bit A/D board (National Instruments, USA) or a signal analyzer (35665 A, HewlettPackard, USA). The current stimulator (A395, World Precision Instruments, USA) was controlled by custom software (LabVIEW, National Instruments, USA).

Cholesterol depletion and salicylate administration

Baseline cochlear microphonics, acoustic, and electrically evoked movements were measured in the untreated temporal bone preparation until stable repeatable values were obtained. media through the apical opening. A tube from the earphone is connected to a rubber O-ring cemented to the remains of the external auditory meatus (not shown). The entire preparation is submerged in artificial perilymph. b Schematic of a radial section of the apical cochlea showing the relative position of the micropipette and the organ of Corti. Laser (arrowhead) for interferometry is focused on a highly reflective Hensen's cell lipid droplet. High-speed confocal imaging and time-resolved measurements are also made through a similar opening. c A single trace of electromechanically evoked displacement riding on top of smaller acoustically evoked vibrations

Membrane cholesterol was depleted by adding $1 \mathrm{mM}$ methyl$\beta$-cyclodextrin ( $\mathrm{M} \beta \mathrm{CD}$, Sigma) to the oxygenated MEM perfusing the temporal bone, and the measures were repeated. In three preparations, the $\mathrm{M} \beta \mathrm{CD}$ perfusate was rinsed from the reservoir and MEM containing $10 \mathrm{mM}$ of NaSal was added. Perfusion was continued until a change in the electromechanical response was observed at which time the NaSal perfusate was rinsed and replaced with normal MEM.

\section{Results}

Exposure to $\mathrm{M} \beta \mathrm{CD}$ enhances the electrical-mechanical response

Glass electrodes positioned in scala media were used to inject electrical currents (Fig. 1). In response to positive current, which depolarizes outer hair cells, Hensen's cells moved toward scala vestibuli, the $+10 \mu \mathrm{A}$ current step in Fig. 2 a evoking a $30-\mathrm{nm}$ position shift. This position shift closely followed the input waveform, although the onset and offset of the mechanical responses were slower than the command voltage applied to the constant current stimulator. Having reached the plateau, the amplitude remained stable 
a

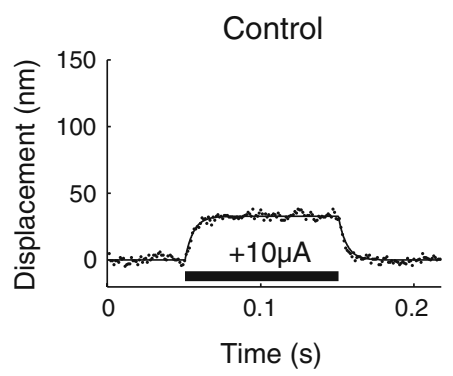

d

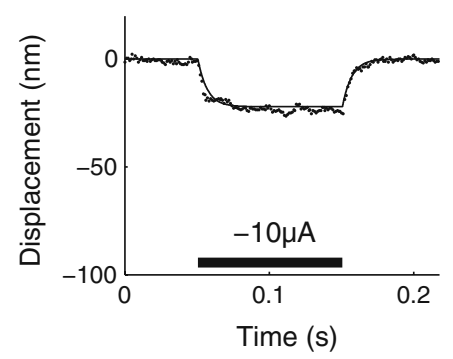

b

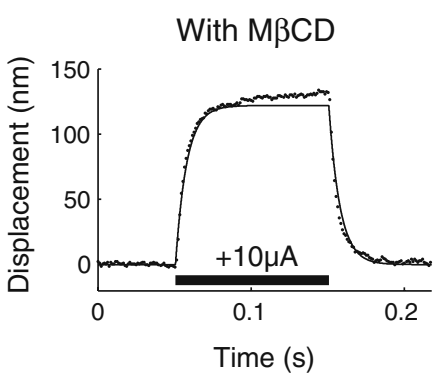

e

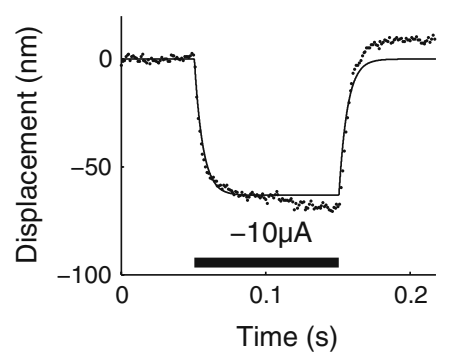

C

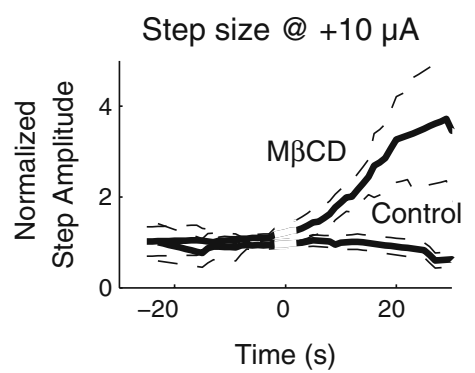

$\mathbf{f}$

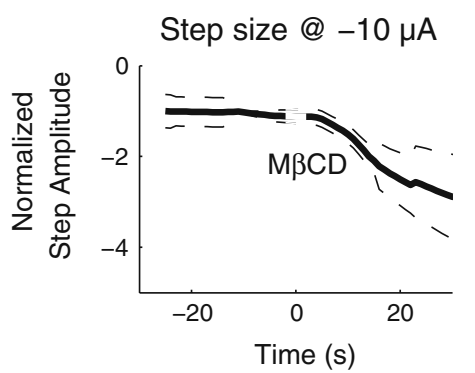

Fig. 2 Electromechanical response of the apical cochlear partition. a-c Response to positive and $\mathbf{d}-\mathbf{f}$ negative $10-\mu \mathrm{A}$ current injections. Control responses $(a, d)$ and the response from the same preparation after perfusion with $1 \mathrm{mM} \mathrm{M} \beta \mathrm{CD}(\mathrm{b}$, e) from a representative preparation. The responses are fit to single exponential functions (thin solid lines). c, f Summary data for nine preparations showing the evolution of the normalized response to $\pm 10-\mu \mathrm{A}$ current injections. Summary responses are normalized to the control response $20 \mathrm{~min}$ prior to perfusion. The dashed lines show standard error of the mean at each time interval. Values at zero time have been blanked out because the mean and S.E.M. were fit with a 5-point sliding interpolation function which introduced artifactual values at zero time. The top summary plot panel also shows the evolution of the normalized response to positive currents in six control preparations. The values were collected for $20 \mathrm{~min}$ before and after $1.5 \mathrm{~h}$ of cochlear perfusion $(\mathrm{M} \beta \mathrm{CD}$ was typically perfused between 1 and $1.5 \mathrm{~h}$ of initiating cochlear perfusion) for the duration of the current step. After applying $1 \mathrm{mM}$ of $\mathrm{M} \beta \mathrm{CD}$, which depletes membrane cholesterol, the magnitude of the position shift increased to $125 \mathrm{~nm}$ (Fig. 2b). In addition, a slow displacement increase was observed with the Hensen's cells continuing to move toward the scala vestibuli until the end of the current step. On average, the magnitude of the position shift increased from $56 \pm 9 \mathrm{~nm}$ to $163 \pm 23 \mathrm{~nm}$ during $\mathrm{M} \beta \mathrm{CD}$ perfusion (mean \pm S.E.M., $n=9$; $p=0.0003$ by the Wilcoxon rank sum test).

Figure $2 \mathrm{c}$ shows that the step amplitude was stable before $\mathrm{M} \beta \mathrm{CD}$ application. The increase of the response was evident minutes after its application, and the maximal increase generally occurred after $20-30 \mathrm{~min}$. In several preparations, the electrically evoked responses started declining thereafter, a change reflected as an increased standard error for the late time points in Fig. 2c. Control amplitudes in the absence of $\mathrm{M} \beta \mathrm{CD}$ were stable, although a tendency to a decrease toward the end of the recording period was evident (Fig. 2c, lower thick line). The stability of current-evoked responses in the absence of $\mathrm{M} \beta \mathrm{CD}$ is evident from the small standard errors of the normalized control amplitudes throughout the experiment.

Responses to negative currents were also altered by $\mathrm{M} \beta \mathrm{CD}$ perfusion. In the absence of the drug, a $10-\mu \mathrm{A}$ current produced an $\sim 20$-nm position shift directed at scala tympani (Fig. 2d), which increased to $60 \mathrm{~nm}$ after $20 \mathrm{~min}$ of $\mathrm{M} \beta \mathrm{CD}$ perfusion (Fig. 2e). A slow drift in position was evident also in this recording, but this effect persisted beyond the duration of the current step. Note that Hensen's cells did not return to their baseline position at the end of the current step but rather overshot it by some $10 \mathrm{~nm}$, a pattern seen in several preparations. The time course of changes in response magnitude was similar for positive and negative currents (compare Fig. 2c and f). On average, negative current responses increased from $39 \pm 9$ to $89 \pm 10 \mathrm{~nm}$ due to removal of membrane cholesterol $(p=0.006)$.

To ascertain whether the kinetics of electrically evoked mechanical responses was affected by cholesterol depletion, the data were fit with a low-pass filtered version of the command voltage driving the constant current generator. In the case shown in Fig. 2a, the time constant was $5.4 \mathrm{~ms}$ with an amplitude of $33 \mathrm{~nm}$. The time constant became slightly slower ( $7.3 \mathrm{~ms}$, Fig. 2b) during $\mathrm{M} \beta \mathrm{CD}$ perfusion and as noted above, the amplitude increased by a factor close to 4 . Due to the slowly changing position during the plateau, we could not fit this part of the response using this simple function alone. Overall, the response kinetics showed no significant change due to $\mathrm{M} \beta \mathrm{CD}$ perfusion (before $\mathrm{M} \beta \mathrm{CD}$, 
$11.5 \pm 1.6 \mathrm{~ms}$, mean \pm S.E.M.; $9.1 \pm 1 \mathrm{~ms}$ during $\mathrm{M} \beta \mathrm{CD} ; p=$ 0.26 by the Wilcoxon rank sum test, $n=9$ ).

As evident from the data presented above, positive currents resulted in larger responses than negative ones. The ratio was about 1.5 , increasing to $\sim 1.8$ during $\mathrm{M} \beta \mathrm{CD}$ perfusion (Fig. 3a). The time course of this change was similar to that seen in Fig. 2c, f. M $\beta C D$ not only changed the magnitude of the electrically evoked response, but also the relation between applied current and the step size. In the absence of the drug, the current step amplitude relation was nearly linear, with a slight tendency to a shallower slope in the negative current region. This tendency to response saturation was more pronounced after $\mathrm{M} \beta \mathrm{CD}$, but positive currents resulted in responses that grew linearly with a larger slope than the controls (Fig. 3b).

Figure $3 \mathrm{c}$ shows the response to $\mathrm{a}+10-\mu \mathrm{A}$ current injection before and after exposure to $\mathrm{M} \beta \mathrm{CD}$ and NaSal. At 25 min after initiating perfusion with $M \beta C D$, the perfusion reservoir was rinsed three times and perfusion with a $10-\mathrm{mM}$ $\mathrm{NaSal}$ solution was begun. The electromechanical response was rapidly reduced to less than the pre-M $\beta C D$ value consistent with the effect of sodium salicylate on the cochlear amplifier [15, 28, 48]. Salicylate did not completely block the step response as a small, $\sim 10 \mathrm{~nm}$, displacement remained. Rapidly rinsing and replacing the sodium salicylate solution in the perfusion reservoir with normal MEM solution when the response block was first observed resulted in the electromechanical response returning to near the peak values of the post-M $\beta C D$ response (data not shown).

Mechanical and electrical response is similar before and after $\mathrm{M} \beta \mathrm{CD}$ exposure

A possible explanation for the increased electrically evoked responses shown in Figs. 2 and 3 is a reduction in the stiffness of the organ of Corti. Because the force-generating outer hair cells are embedded in a matrix of supporting cells, a change in the stiffness of those surrounding structures will result in an altered electromechanical response. In the absence of an endocochlear potential, sound-evoked mechanical responses are largely determined by the stiffness, mass, and friction of the cochlear structures [32]. An indirect but useful measure of these parameters can be obtained by measuring sound-evoked mechanical responses in the absence of current. Figure $4 \mathrm{a}$ shows the mechanical response to a sound stimulus containing five frequencies centered on the best frequency of the recording location. The waveform acquired during $\mathrm{M} \beta \mathrm{CD}$ perfusion is similar to the control, except for a minor increase in the noise level. Spectral analysis (Fig. 4b) using the Fourier transform corroborates this impression: Although small changes occur at some frequencies, these are within the noise floor. Aside from a slight shift towards higher frequencies, the cochlear microphonic potential also shows little change (Fig. 4c). Minor increases in cochlear microphonic potentials were seen in some preparations during $\mathrm{M} \beta \mathrm{CD}$ perfusion, and small decreases were noted in others. Overall, $\mathrm{M} \beta \mathrm{CD}$ did not affect the amplitude or tuning of these potentials. The data shown in Fig. 4a-c indicate that the passive mechanics of the organ of Corti are unaffected by $\mathrm{M} \beta \mathrm{CD}$, and the lack of change in cochlear microphonics is evidence that forward transduction is impervious to the reduction in cholesterol in the cell bodies of outer hair cells.

Figure 4 demonstrates how exposure to $\mathrm{M} \beta \mathrm{CD}$ can result in an increase of the acoustically evoked response in the presence of a positive current. Positive current, which restores the endocochlear potential in the excised preparation, often results in larger acoustically evoked responses than either no current or negative current and $\mathrm{M} \beta \mathrm{CD}$ could greatly enhance the increase. There was considerable variation in the increase observed following $\mathrm{M} \beta \mathrm{CD}$. In some cases, there would be no increase even with a major enhancement of the electromotile response. In other preparations, there was a modest increase when $\mathrm{M} \beta \mathrm{CD}$ was

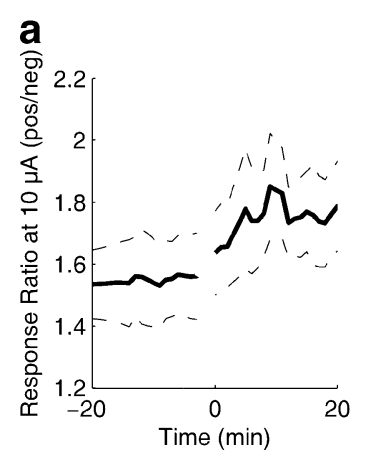

Fig. 3 The magnitude of the response to positive current is greater than the response to negative current and salicylate blocks the electromechanical response. a Summary plot of the ratio of the magnitude of the response to positive current to the magnitude of the negative current for nine preparations. b Response of a representative
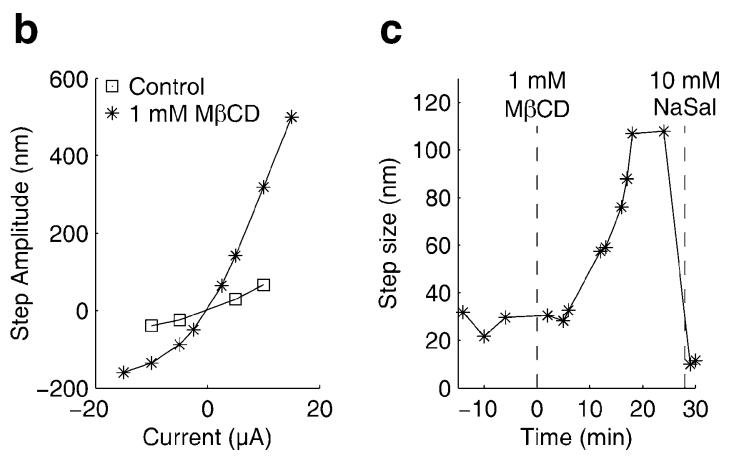

preparation to current steps of different magnitude before and after perfusion with $\mathrm{M} \beta \mathrm{CD}$. $\mathbf{c}$ Electromechanical responses over time from a representative preparation to $+10-\mu \mathrm{A}$ current injections showing typical increase in response to $\mathrm{M} \beta \mathrm{CD}$ perfusion followed by a rapid decline in response to perfusion with $10 \mathrm{mM} \mathrm{NaSal}$ 
a
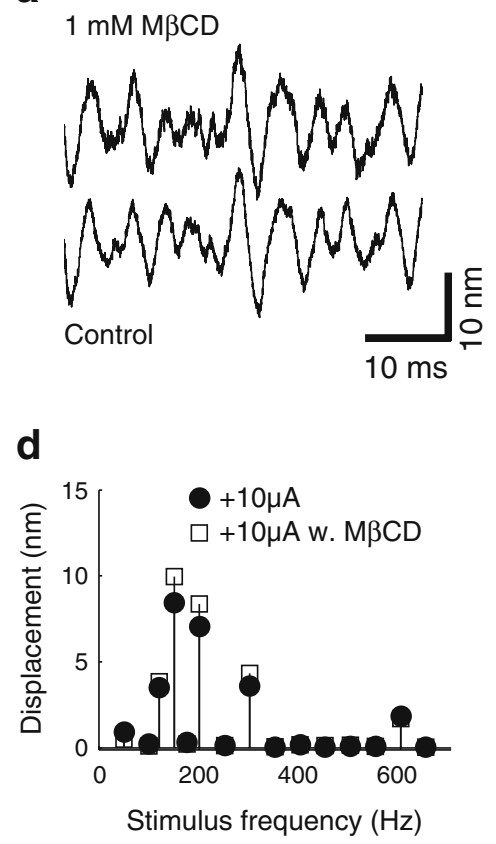

b

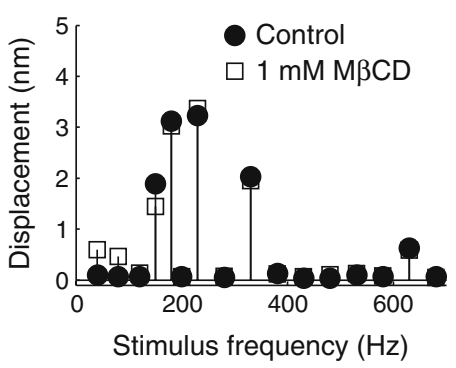

e

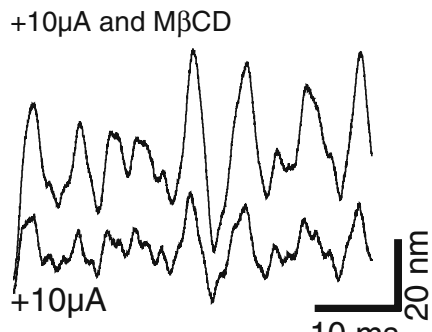

C

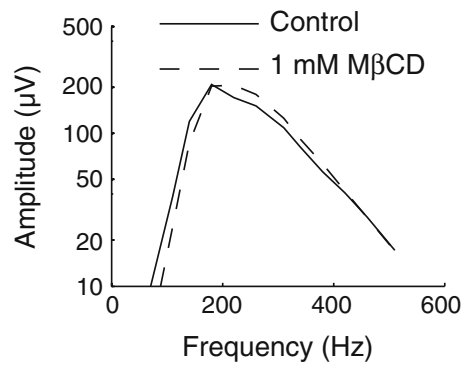

f

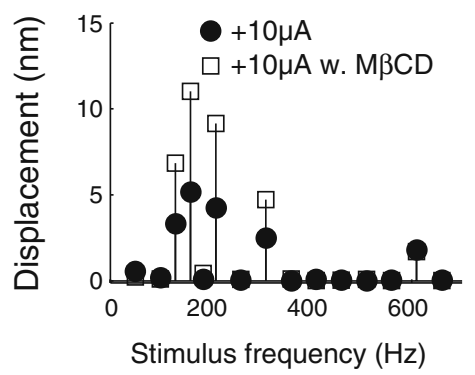

Fig. 4 Cochlear partition tuning and cochlear microphonics are similar before and after exposure to $\mathrm{M} \beta \mathrm{CD}$. a Time domain and $\mathbf{b}$ spectral analysis of sound-evoked mechanical response. c Cochlear microphonics from the same preparation as $\mathrm{a}$ and $\mathrm{b}$ are similar before and after $\mathrm{M} \beta \mathrm{CD}$. d Spectra from another preparation showing a

present (Fig. 4d). Figure 4e, f show a preparation in which $\mathrm{M} \beta \mathrm{CD}$ resulted in a 6-dB boost at best frequency. The increase of sound-evoked motion amplitudes during $\mathrm{M} \beta \mathrm{CD}$ may be seen in Fig. 4e and is analyzed in more detail in Fig. 4f. Responses near the best frequency $(200 \mathrm{~Hz})$ are more than doubled, but smaller changes are seen at $300 \mathrm{~Hz}$, and no change at all at $600 \mathrm{~Hz}$. Thus, although positive current increases sound-evoked responses and sharpness of tuning during $\mathrm{M} \beta \mathrm{CD}$ perfusion, there is no shift in the best frequency. In summary, while electromotility is clearly an important component of the cochlear amplifier [14], an increase in electromotility does not automatically produce increased amplification of sound-evoked motion.

Figure 5 shows another example of increased cochlear amplification following $\mathrm{M} \beta \mathrm{CD}$ perfusion. Time-resolved confocal imaging and optical flow computation $[22,26]$ was used to measure sound-evoked responses. Acoustically evoked motions were nearly perpendicular to the reticular lamina during negative current injections, with a peak amplitude of approximately $300 \mathrm{~nm}$ (black trajectory in Fig. 5a). Positive current increased perpendicular vibrations to $\sim 360 \mathrm{~nm}$ (gray trajectory in Fig. 5a). The parallel motion component, directed along the horizontal axis of the image, appears more responsive to positive current and consequently shows a larger increase than the vertical component. modest increase in sound-evoked response during a $+10-\mu \mathrm{A}$ current injection following exposure to $\mathrm{M} \beta \mathrm{CD}$. e Time domain and $\mathbf{f}$ spectral analysis of sound-evoked response during a $+10-\mu \mathrm{A}$ current injection from a preparation showing greater response following $\mathrm{M} \beta \mathrm{CD}$

After $10 \mathrm{~min}$ of $\mathrm{M} \beta \mathrm{CD}$ perfusion at $1 \mathrm{mM}$, negative current vibrations were unchanged, as seen by comparing the black trajectories in Fig. 5a, b. The peak amplitude remained close to $300 \mathrm{~nm}$, and the major axis of the trajectory remains in the same orientation. Thus, during negative currents, sound-evoked vibrations are quite stable and not significantly affected by $\mathrm{M} \beta \mathrm{CD}$. However, soundevoked responses during positive current were increased. Note that the amplitude increases more for movements parallel to the reticular lamina giving the trajectory a more elliptic shape (gray trajectory in Fig. 5b). This is an important change, as it would be expected to be more effective in deflecting hair cell stereocilia.

The cellular components of the cochlear partition remain intact following $\mathrm{M} \beta \mathrm{CD}$ exposure

Short-term perfusions with $\mathrm{M} \beta \mathrm{CD}(<1 \mathrm{~h})$ did not produce obvious morphological changes in the organ of Corti, as evidenced by confocal imaging of the measurement site after loading cells with the fluorescent membrane dye RH795. In Fig. 6a, note that Reissner's membrane retains its normal honeycomb configuration and that supporting cells near the measurement site all appear intact. The cell membranes of supporting cells were clearly labeled, and the lipid droplets inside Hensen's cells are also visible. Fragmentation of lipid 

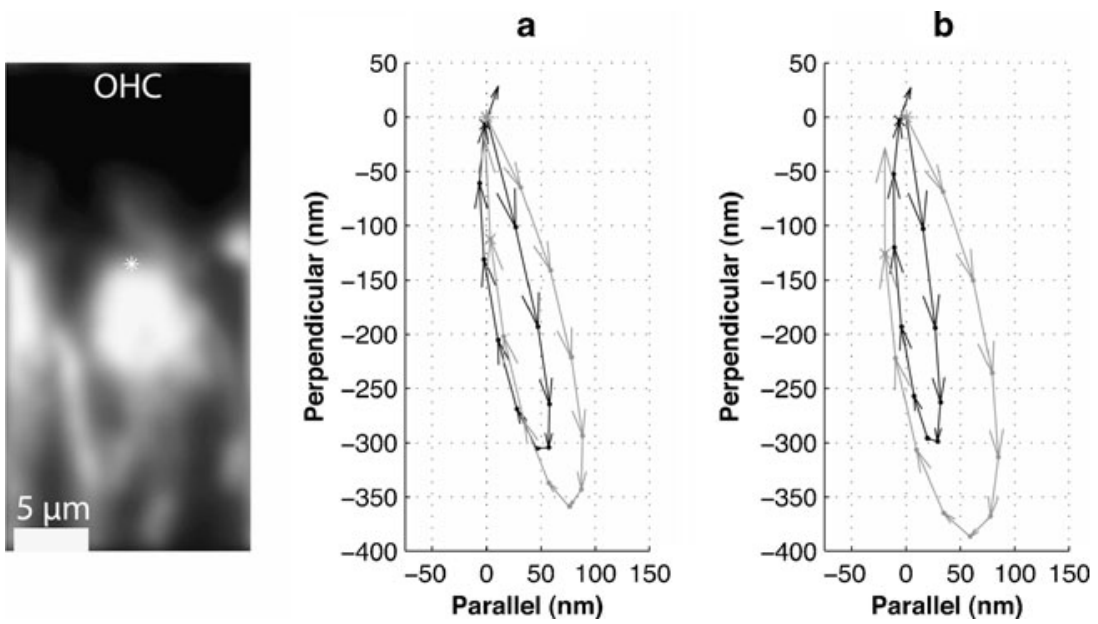

Fig. 5 Confocal imaging of sound-evoked vibrations confirms a larger effect of positive current injection following $\mathrm{M} \beta \mathrm{CD}$. Confocal image on the left of outer hair cell recorded in situ during simultaneous sound and electrical stimulation. Vibrations at the base of the stereocilia bundle were measured at a point on the reticular

droplets, a common sign of acute cellular stress in the cochlear apex, was not observed. On focusing deeper into the organ of Corti (Fig. 6b), it is seen that outer and IHC appear normal with clearly delineated cell membranes showing no signs of swelling or other structural abnormalities. The section through the organ of Corti is oblique and the full length of the OHC bodies cannot be inspected in this image. However, preparations with long-term exposure $(>1 \mathrm{~h})$ to $\mathrm{M} \beta \mathrm{CD}$ frequently, but not always, showed pathology, most commonly OHC shrinkage.

The antifungal macrolide filipin is highly fluorescent and binds specifically to membranes containing cholesterol and can therefore be used for visualizing such membranes. It was used to image the organ of Corti in control samples (Fig. 6c) as well as samples treated with $\mathrm{M} \beta \mathrm{CD}$ (Fig. $6 \mathrm{~d}$ ). While there was a decrease in staining intensity in $\mathrm{M} \beta C D$-treated samples, labeling was still observed in all cell types in the organ of Corti, confirming that removal of cholesterol with $\mathrm{M} \beta \mathrm{CD}$ is incomplete. Preparations that were not exposed to filipin had autofluorescence that was at least one order of magnitude smaller than the fluorescence intensity observed in filipin treated samples (Fig. 6c, d). The M $\beta C D$-induced decrease in intensity should be interpreted with caution given the difficulty in quantifying fluorescent labels such as filipin.

\section{Discussion}

The site of action is the outer hair cell

The increase in the electromechanical response observed on exposure to $\mathrm{M} \beta \mathrm{CD}$ most likely results from the depletion of cholesterol from the plasma membrane of OHCs. We have lamina marked by the dot. a, b Acoustically evoked vibration trajectories during negative (dark arrows) and positive (gray arrows) stimulation before (a) and after (b) exposure to $\mathrm{M} \beta \mathrm{CD}$. Movements parallel to the reticular lamina are plotted along the abscissa while perpendicular movements are plotted along the ordinate

previously reported on how membrane cholesterol alters prestin-associated charge movement in prestin-transfected HEK cells. Decreasing membrane cholesterol shifts prestinassociated charge movement towards more depolarized membrane potentials and increased the charge density [46].
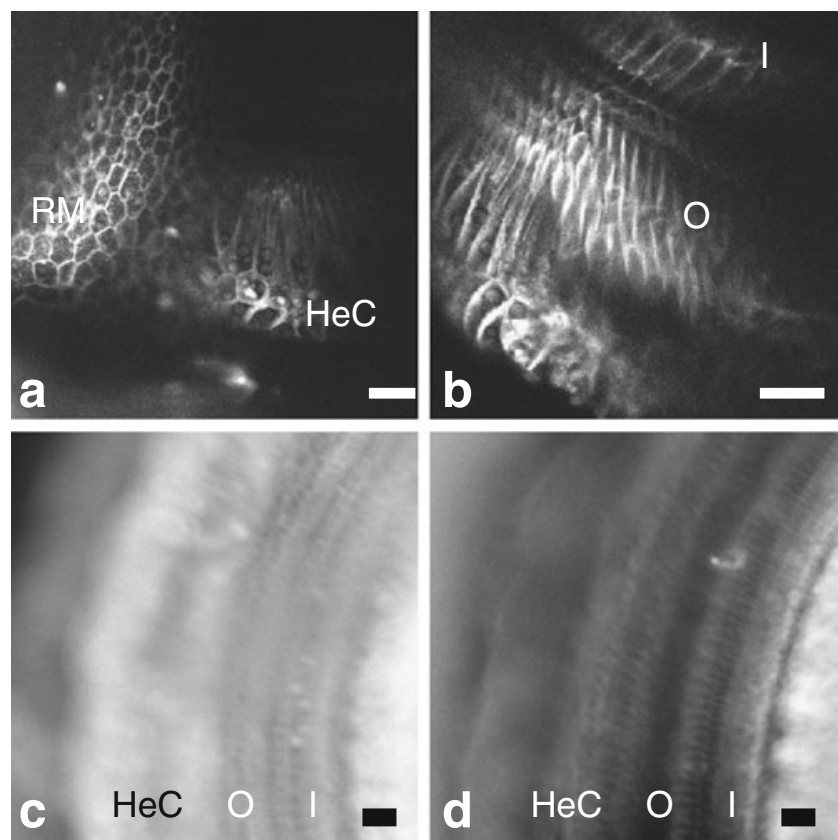

Fig. 6 Cochlear histology following $\mathrm{M} \beta \mathrm{CD}$ exposure. a, b Confocal images of the cochlea after 10 min of perfusion with RH795. a Optical section through Reissner's membrane $(R M)$ and Hensen's cells $(\mathrm{HeC})$ near the site of vibration measurements. b Optical section through the organ of Corti at a deeper focal plane than a. ( $I$, inner hair cells; $O$, outer hair cells). c UV fluorescence microscopy of filipin-labeled organ of Corti in a control preparation not exposed to $\mathrm{M} \beta \mathrm{CD}$. d Filipin labeling in a preparation perfused with $1 \mathrm{mM} \mathrm{M} \beta C D$. All scale bars $=25 \mu \mathrm{m}$ 
During cochlear development, the concentration of cholesterol in the OHC lateral wall decreases [37, 42] while the subsurface cisternae appear and mature [55]. At the same time, there is an increase in $\mathrm{OHC}$ electromotility $[5,23]$ accompanied by a depolarizing shift in prestin-associated charge movement and an increase in its charge density $[1,40]$. The increase in the cochlear electromechanical response we observe resembles the developmental increase in $\mathrm{OHC}$ electromotility that is concurrent with a decrease in plasma membrane cholesterol. Sodium salicylate has long been known to block OHC electromotility [15, 28, 48]. The reversible reduction of the $\mathrm{M} \beta \mathrm{CD}$-enhanced response with sodium salicylate further supports the site of action of $\mathrm{M} \beta \mathrm{CD}$ as the $\mathrm{OHC}$ lateral wall plasma membrane.

The absence of an M $\beta C D$-dependent change in cochlear microphonics implies that membrane cholesterol depletion was confined to cells exposed to scala tympani perfusion including the portion of Reissner's membrane from the helicotrema to the recording site. Filipin labeled the exposed cells, and cochlear microphonics remained unchanged indicating Reissner's membrane was functionally intact. The continuation of an electromechanical response is further testimony to the continued integrity of Reissner's membrane because its damage results in an altered impedance that would alter the electromechanical response.

Implications of the $\mathrm{M} \beta \mathrm{CD}$ response increase on cholesterol trafficking in the $\mathrm{OHC}$

Measuring OHC reactive charge movement simultaneously with electromotile length changes reveals that the voltage dependence for normalized length changes is quantitatively identical to the voltage dependence of the normalized reactive charge movement $[24,53]$. This supports the use of the reactive, prestin-associated current as equivalent to electromotility. Exposure to $\mathrm{M} \beta \mathrm{CD}$ increases the electromechanical response to positive current by approximately four times (Fig. 2c) which is more than twice what would be expected from the effect of cholesterol depletion on prestin-associated charge density [46].

Immunohistochemical labeling suggests that prestin is uniformly distributed along the $\mathrm{OHC}$ lateral plasma membrane [56]. Prestin function, however, is not uniform; it is non-functional at the synaptic pole [25] and has a nonuniform distribution along the lateral wall [52]. Mechanically evoked prestin-associated charge movement is maximal midway between the cuticular plate and the nucleus. A plausible explanation for the non-uniform distribution would be a cholesterol concentration gradient that reaches a minimal value in the middle of the cell. This cholesterol concentration gradient is apparent in photomicrographs of filipin-stained OHCs [37] and is consistent with the lower fluorescence we observe in the $\mathrm{OHC}$ region of Fig. $6 \mathrm{c}$. The "specific" prestin-associated charge movement would be maximal in the region with the least cholesterol and decrease with increasing cholesterol concentration [46] towards either end. In addition, the voltage at maximum gain for the charge movement will hyperpolarize as cholesterol increases further reducing prestin function at normal holding potentials. The net result is that the prestin residing towards the ends of the $\mathrm{OHC}$ would appear to be non-functional. The non-uniform distribution of cholesterol in normal OHCs would lower the whole-cell electromechanical response to less than what it would be if the cholesterol concentration were uniformly low. $\mathrm{M} \beta \mathrm{CD}$ exposure would reduce the cholesterol concentration towards the level at the middle of the cell and the total "whole-cell" charge density would increase by more than a factor of two, consistent with the observed increase in cochlear electromechanics (Fig. 2c).

The mechanism by which cholesterol is maintained at a low concentration in the lateral wall membrane is not known but is likely to involve lipid trafficking with the subsurface cisternae. Membrane turnover occurs at the apex and the base of the $\mathrm{OHC}[30,38]$, and the newly added membrane would be expected to have a normal eukaryotic plasma membrane cholesterol concentration. Cholesterol will diffuse from membrane recently enriched by exocytosis at the base and apex of the OHC and, in the absence of any other contribution to cholesterol trafficking, the concentration will equilibrate throughout the basolateral plasma membrane. If the subsurface cisternae actively sequester cholesterol from the plasma membrane, the cholesterol concentration will decrease until it reaches a minimum value near the middle of the lateral wall. Both immunohistochemical [56] and immunogold [34] labeling of prestin in OHCs indicate that prestin density is less in the basal pole than in the lateral wall. The reduced prestin may be the result of prestin recycling which has been shown to increase with deglycosylation and increased cholesterol [43]. Prestin recycling cannot occur in the lateral wall because the cortical lattice and subsurface cisternae prevent vesicular trafficking. The reduced prestin may contribute to the absence of prestin function observed in the synaptic pole of the $\mathrm{OHC}$.

Implications for hearing health

Serum dyslipidemia The impact of serum dyslipidemia on cardiovascular health is well-known, and heart disease is a major public health concern. There is little information as to how serum dyslipidemia might lead to alterations in the lipid composition of cell membranes. The mechanisms underlying cellular membrane cholesterol homeostasis have been studied for many years and involve a variety of regulatory feedback pathways within cells. The relation between serum dyslipidemia and hearing is further confounded by the limited 
vascularization of the organ of Corti (presumably to minimize cardiovascular pressure changes so that we do not hear our pulse). There are reports of a correlation between serum dyslipidemia and hearing loss [16, 41, 47] that are balanced by other reports finding no correlation. Two animal studies have suggested that hearing problems associated with age or resulting from a lipid challenge are ameleriorated with statins $[11,51]$. Systemic administration of a $\beta$-cyclodextrin has been used to treat animal models of Niemann-Pick type $C$ disease. The treatments generally resolve the major problems of the disease, but a non-reversible hearing loss was observed in cats [54]. The hearing loss is consistent with the loss of distortion product otoacoustic emissions we observed with $\mathrm{M} \beta C D$ [42]. Hair cell membranes are buffered by a variety of processes involved in cholesterol trafficking when dyslipidemia is treated with statins. These are bypassed with the $\beta$-cyclodextrin approach, suggesting that care must be taken to not be too aggressive in attempting to modulate membrane cholesterol in the ear.

Aging Aging is associated with a drop in endocochlear potential $[39,45]$ which may be linked to conventional atherosclerotic cholesterol involvement reducing perfusion of the stria vascularis. The low endocochlear potential is mimicked in our study by the no current condition. The cochlear electromechanical response is increased either by restoring the endocochlear potential with a positive current or by reducing membrane cholesterol levels. Our findings suggest that restoring the endocochlear potential and decreasing membrane cholesterol may improve some forms of geriatric hearing loss.

Acknowledgements This research was supported by research grants R01 DC000354 and DC002775 from NIH/NIDCD (WEB), by the Tysta skolan foundation, Hörselskadades Riksförbund, and Wallenberg foundations, funds of Karolinska Institutet, and the Swedish Research Council (622-2003-6079; K2008-63X-14061-08-3). PH is a WennerGren Foundation fellow.

Open Access This article is distributed under the terms of the Creative Commons Attribution Noncommercial License which permits any noncommercial use, distribution, and reproduction in any medium, provided the original author(s) and source are credited.

\section{References}

1. Abe T, Kakehata S, Kitani R, Maruya S, Navaratnam D, SantosSacchi J, Shinkawa H (2007) Developmental expression of the outer hair cell motor prestin in the mouse. J Membr Biol 215:49-56

2. Adler HJ, Belyantseva IA, Merritt RC Jr, Frolenkov GI, Dougherty GW, Kachar B (2003) Expression of prestin, a membrane motor protein, in the mammalian auditory and vestibular periphery. Hear Res 184:27-40
3. Alberts B (2002) Molecular biology of the cell, 4th edn. Garland Science, New York

4. Ashmore J, Avan P, Brownell WE, Dallos P, Dierkes K, Fettiplace R, Grosh K, Hackney CM, Hudspeth AJ, Julicher F, Lindner B, Martin P, Meaud J, Petit C, Sacchi JR, Canlon B (2010) The remarkable cochlear amplifier. Hear Res 266:117

5. Belyantseva IA, Adler HJ, Curi R, Frolenkov GI, Kachar B (2000) Expression and localization of prestin and the sugar transporter GLUT-5 during development of electromotility in cochlear outer hair cells. J Neurosci 20:116

6. Brownell WE (2006) The piezoelectric outer hair cell. In: Fay RR, Popper AN (eds) Vertebrate hair cells. Springer, New York, pp 313-347

7. Brownell WE, Oghalai JS (2000) Structural basis of outer hair cell motility or where's the motor? In: Lim DJ (ed) Cell and molecular biology of the ear. Kluwer Academic/Plenum Press, New York, pp 69-83

8. Brownell WE, Bader CR, Bertrand D, de Ribaupierre Y (1985) Evoked mechanical responses of isolated cochlear outer hair cells. Science 227:194-196

9. Brownell WE, Spector AA, Raphael RM, Popel AS (2001) Microand nanomechanics of the cochlear outer hair cell. Annu Rev Biomed Eng 3:169-194

10. Brundin L, Flock B, Flock Å (1992) Sound induced displacement response of the guinea pig hearing organ and its relation to the cochlear potentials. Hear Res 58:175-184

11. Cai Q, Du X, Zhou B, Cai C, Kermany MH, Zhang C, Yoo T (2009) Effects of simvastatin on plasma lipoproteins and hearing loss in apolipoprotein E gene-deficient mice. ORL J Otorhinolaryngol Relat Spec 71:244-250

12. Cooper GM (2000) The cell: a molecular approach, 2nd edn. Sinauer Associates, Sunderland

13. Dallos P, Evans BN, Hallworth R (1991) Nature of the motor element in electrokinetic shape changes of cochlear outer hair cells. Nature 350:155-157

14. Dallos P, Wu X, Cheatham MA, Gao J, Zheng J, Anderson CT, Jia S, Wang X, Cheng WH, Sengupta S, He DZ, Zuo J (2008) Prestin-based outer hair cell motility is necessary for mammalian cochlear amplification. Neuron 58:333-339

15. Dieler R, Shehata-Dieler WE, Brownell WE (1991) Concomitant salicylate-induced alterations of outer hair cell subsurface cisternae and electromotility. J Neurocytol 20:637-653

16. Evans MB, Tonini R, Shope CD, Oghalai JS, Jerger JF, Insull W Jr, Brownell WE (2006) Dyslipidemia and auditory function. Otol Neurotol 27:609-614

17. Flock A, Scarfone E, Ulfendahl M (1998) Vital staining of the hearing organ: visualization of cellular structure with confocal microscopy. Neuroscience 83:215-228

18. Forge A (1991) Structural features of the lateral walls in mammalian cochlear outer hair cells. Cell Tissue Res 265:473-483

19. Frank G, Hemmert W, Gummer AW (1999) Limiting dynamics of high-frequency electromechanical transduction of outer hair cells. Proc Natl Acad Sci U S A 96:4420-4425

20. Fridberger A, de Monvel JB (2003) Sound-induced differential motion within the hearing organ. Nat Neurosci 6:446-448

21. Fridberger A, Widengren J, Boutet de Monvel J (2004) Measuring hearing organ vibration patterns with confocal microscopy and optical flow. Biophys J 86:535-543

22. Fridberger A, Tomo I, Ulfendahl M, Boutet de Monvel J (2006) Imaging hair cell transduction at the speed of sound: dynamic behavior of mammalian stereocilia. Proc Natl Acad Sci USA 103:1918-1923

23. He DZ, Evans BN, Dallos P (1994) First appearance and development of electromotility in neonatal gerbil outer hair cells. Hear Res 78:77-90 
24. Homma K, Dallos P (2010) Evidence that prestin has at least two voltage-dependent steps. J Biol Chem 286:2297-2307

25. Huang G, Santos-Sacchi J (1994) Motility voltage sensor of the outer hair cell resides within the lateral plasma membrane. Proc Natl Acad Sci U S A 91:12268-12272

26. Jacob S, Tomo I, Fridberger A, de Monvel JB, Ulfendahl M (2007) Rapid confocal imaging for measuring sound-induced motion of the hearing organ in the apical region. J Biomed Opt 12:021005

27. Jacob S, Johansson C, Ulfendahl M, Fridberger A (2009) A digital heterodyne laser interferometer for studying cochlear mechanics. J Neurosci Methods 179:271-277

28. Kakehata S, Santos-Sacchi J (1996) Effects of salicylate and lanthanides on outer hair cell motility and associated gating charge. J Neurosci 16:4881-4889

29. Kalinec F, Holley MC, Iwasa KH, Lim DJ, Kachar B (1992) A membrane-based force generation mechanism in auditory sensory cells. Proc Natl Acad Sci U S A 89:8671-8675

30. Kaneko T, Harasztosi C, Mack AF, Gummer AW (2006) Membrane traffic in outer hair cells of the adult mammalian cochlea. Eur $\mathrm{J}$ Neurosci 23:2712-2722

31. Liberman MC, Gao J, He DZ, Wu X, Jia S, Zuo J (2002) Prestin is required for electromotility of the outer hair cell and for the cochlear amplifier. Nature 419:300-304

32. Lighthill MJ (1981) Energy flow in the cochlea. J Fluid Mech 106:149-213

33. Ludwig J, Oliver D, Frank G, Klocker N, Gummer AW, Fakler B (2001) Reciprocal electromechanical properties of rat prestin: the motor molecule from rat outer hair cells. Proc Natl Acad Sci USA 98:4178-4183

34. Mahendrasingam S, Beurg M, Fettiplace R, Hackney CM (2010) The ultrastructural distribution of prestin in outer hair cells: a postembedding immunogold investigation of low-frequency and highfrequency regions of the rat cochlea. Eur J Neurosci 31:1595-1605

35. Maier H, Zinn C, Rothe A, Tiziani H, Gummer AW (1997) Development of a narrow water-immersion objective for laserinterferometric and electrophysiological applications in cell biology. J Neurosci Methods 77:31-41

36. Mammano F, Ashmore JF (1993) Reverse transduction measured in the isolated cochlea by laser Michelson interferometry. Nature 365:838-841

37. Nguyen TV, Brownell WE (1998) Contribution of membrane cholesterol to outer hair cell lateral wall stiffness. Otolaryngol Head Neck Surg 119:14-20

38. Oghalai JS, Patel AA, Nakagawa T, Brownell WE (1998) Fluorescence-imaged microdeformation of the outer hair cell lateral wall. J Neurosci 18:48-58

39. Ohlemiller KK (2009) Mechanisms and genes in human strial presbycusis from animal models. Brain Res 1277:70-83

40. Oliver D, Fakler B (1999) Expression density and functional characteristics of the outer hair cell motor protein are regulated during postnatal development in rat. J Physiol 519(Pt 3):791-800
41. Preyer S, Baisch A, Bless D, Gummer AW (2001) Distortion product otoacoustic emissions in human hypercholesterolemia. Hear Res 152:139-151

42. Rajagopalan L, Greeson JN, Xia A, Liu H, Sturm A, Raphael RM, Davidson AL, Oghalai JS, Pereira FA, Brownell WE (2007) Tuning of the outer hair cell motor by membrane cholesterol. J Biol Chem 282:36659-36670

43. Rajagopalan L, Organ-Darling LE, Liu H, Davidson AL, Raphael RM, Brownell WE, Pereira FA (2010) Glycosylation regulates prestin cellular activity. J Assoc Res Otolaryngol 11:39-51

44. Santi PA, Mancini P, Barnes C (1994) Identification and localization of the GM1 ganglioside in the cochlea using thin-layer chromatography and cholera toxin. J Histochem Cytochem 42:705-716

45. Schuknecht HF, Gacek MR (1993) Cochlear pathology in presbycusis. Ann Otol Rhinol Laryngol 102:1-16

46. Sfondouris J, Rajagopalan L, Pereira FA, Brownell WE (2008) Membrane composition modulates prestin-associated charge movement. J Biol Chem 283:22473-22481

47. Shargorodsky J, Curhan SG, Eavey R, Curhan GC (2010) A prospective study of cardiovascular risk factors and incident hearing loss in men. Laryngoscope 120:1887-1891

48. Shehata WE, Brownell WE, Dieler R (1991) Effects of salicylate on shape, electromotility and membrane characteristics of isolated outer hair cells from guinea pig cochlea. Acta Otolaryngol 111:707-718

49. Sturm AK, Rajagopalan L, Yoo D, Brownell WE, Pereira FA (2007) Functional expression and microdomain localization of prestin in cultured cells. Otolaryngol Head Neck Surg 136:434 439

50. Sun SX, Farrell B, Chana MS, Oster G, Brownell WE, Spector AA (2009) Voltage and frequency dependence of prestinassociated charge transfer. J Theor Biol 260:137-144

51. Syka J, Ouda L, Nachtigal P, Solichova D, Semecky V (2007) Atorvastatin slows down the deterioration of inner ear function with age in mice. Neurosci Lett 411:112-116

52. Takahashi S, Santos-Sacchi J (2001) Non-uniform mapping of stress-induced, motility-related charge movement in the outer hair cell plasma membrane. Pflugers Arch 441:506-513

53. Wang X, Yang S, Jia S, He DZ (2010) Prestin forms oligomer with four mechanically independent subunits. Brain Res 1333:28-35

54. Ward S, O'Donnell P, Fernandez S, Vite CH (2010) 2-hydroxypropylbeta-cyclodextrin raises hearing threshold in normal cats and in cats with Niemann-Pick type C disease. Pediatr Res 68:52-56

55. Weaver SP, Schweitzer L (1994) Development of gerbil outer hair cells after the onset of cochlear function: an ultrastructural study. Hear Res 72:44-52

56. Yu N, Zhu ML, Zhao HB (2006) Prestin is expressed on the whole outer hair cell basolateral surface. Brain Res 1095:51-58

57. Zheng J, Shen W, He DZ, Long KB, Madison LD, Dallos P (2000) Prestin is the motor protein of cochlear outer hair cells. Nature 405:149-155 